\title{
DOS IMÁGENES DEL LABERINTO: BORGES Y GABRIEL FERRATER*
}

\section{Josep Besa Camprubí}

\author{
Universitat Autònoma de Barcelona
}

Par le mot par commence donc ce texte

Dont la première ligne dit la vérité (Francis Ponge)

Llevaba razón Ayala-Dip cuando, en una breve pero rica contribución a un seminario sobre Walter Benjamín y el espíritu de la modernidad promovido por el Institut d'Humanitats de Barcelona con motivo del cincuentenario de la muerte y el centenario del nacimiento del escritor alemán (Ayala-Dip, 1993), argumentaba que en el presente de la poesía

* Este escrito tiene una deuda confesable: algunas de las ideas que en él expongo las sugirió la lectura de un sutil estudio de Dolors Oller sobre «el significado de la forma» (Oller, 1995). Al estudio le precedió, en el tiempo, una conferencia de tema similar pronunciada en el VI Congreso Internacional de la AES (cf. Oller, 1996) y en la que, sirviéndose de Wittgenstein y del poema de Cernuda «Estoy cansado», Oller exploraba «la construcción (deconstrucción incluida) del sentido de la escritura a través de la observación del significado de su forma». En determinados poemas, en efecto, la forma lógica del discurso mimetiza el contenido intencional. Lo iconiza. 
se dejaba sentir la aceptación, por parte del poeta, de que ya no podía hacer nada para recuperar aquello que, según Benjamin, Baudelaire se ocupó de desterrar de su territorio para siempre: la conciencia del poema como principio iluminador de la realidad. En efecto, el único principio que le queda al poema, si le queda alguno, es su propia realidad, esto es, los mecanismos de su construcción. La modernidad significa el repliegue del poeta sobre su propio quehacer, repliegue, continúa Ayala-Dip, que le sitúa en el vértice mismo de su práctica: el lenguaje. El poema, en definitiva, se cierra en sí mismo, que es como decir en su propia escritura, en su propia lectura y en el propio acto poético. Como muy bien dijo Wallace Stevens en 1937, el tema del poema es la poesía.

En este contexto, el que un texto actual, sea en verso o en prosa, hable de, pongamos por caso, Eco, Narciso, Dédalo o Teseo, tendría que llevarnos, como mínimo, a la precaución. Pues todavía hay quien hace del mito mito y ve en él no se sabe ya qué inefables transcendencias. Más cosa que palabra, más fin que medio, más discurso que recurso, la exégesis literaria lo eleva demasiado a menudo al Olimpo del sentido y del contenido, del fondo, de la Verdad, cuando las más de las veces no es más que mero pretexto.

En este escrito vamos a intentar ilustrar las ideas formuladas en los párrafos precedentes mediante el análisis del texto de Borges publicado en Atlas (1984) bajo el título de «El Laberinto» y el del poema de Gabriel Ferrater «Teseo», el último del volumen Les dones $i$ els dies, de 1968 (Mujeres y días en versión al castellano publicada en Seix Barral) ${ }^{1}$.

Sirviéndonos de una de las ideas clave de la semiótica francesa capitaneada por Greimas, podemos decir, para empezar, que tanto en «E1 Laberinto» como en «Teseo» el mito formaría parte del com-

1 Mujeres y días (Barcelona, 1979) no contiene todos los poemas de Les dones $i$ els dies: si mi recuento no es erróneo, faltan en él diecinueve poemas (el total suma ciento catorce). No obstante, el volumen (1) no se presenta al lector como una antología (por mucho que en su cubierta posterior se nos diga que la edición reúne una «amplia muestra» de Les dones $i$ els dies, y por mucho que el título sea no Las mujeres y los días sino, sólo, Mujeres y días), y (2) contiene un interesante prólogo de Arthur Terry cuya comprensión cabal exigiría no una muestra sino la totalidad del libro (pues el autor - y ello es muy lógico, por otra parte- considera en su análisis no Mujeres y días sino Les dones $i$ els dies: muchos de sus comentarios lo son a textos ausentes, con lo que nos es vedada la posibilidad de contrastarlos). Las versiones son obra no de una sino de tres sólidas plumas: Pere Gimferrer (quince poemas), José Agustín Goytisolo (dieciocho poemas) y José M. Valverde (los sesenta y dos poemas restantes, entre ellos «Teseo»). 
ponente figurativo del discurso y no llegaría a alcanzar, pues, el componente temático, situado en un nivel más profundo. El tema del texto de Borges no es el Laberinto, como tampoco es Teseo el tema del poema de Ferrater. En su trabajo «Pour une sémantique des traditions populaires», Joseph Courtès (1985: 6-7) define lo figurativo como todo contenido de un sistema de representación, sea éste lingüístico o no, poseedor de un correspondant perceptible en el plano de la expresión del mundo «natural» (sea este mundo dado o construido; en el caso del mito, claro está, es construido). Inversamente, el nivel temático corresponde a un investissement semántico abstracto, de naturaleza conceptual, que no posee ninguna atadura o sujeción con el universo del mundo natural. Las relaciones recíprocas entre estos dos niveles del discurso son de carácter complementario. O mejor dicho: si el nivel temático «peut se dire en quelque sorte par lui seul», lo figurativo nunca se encuentra vuelto hacia sí (pues no tendría sentido): siempre está al servicio de lo temático. El trayecto del uno al otro es, pues, necesario para proveer de sentido lo sensible (sin tematización, lo figurativo es insensato). No obstante, esta necesidad no tendría por qué entrañar la confusión entre ambos componentes del discurso, una confusión que acarrea como consecuencia inmediata la atribución de tema a lo que no es sino figura.

$\mathrm{Ni}$ que decir tiene que este recorrido generativo de lo figurativo a lo temático es obra del lector. El tema es siempre una construcción, una hipótesis interpretativa que da coherencia a la lectura. Está claro también que no existe ninguna parte del texto encargada de la elaboración del tema - por mucho que algunas partes (como, por ejemplo, el título y el final del texto) puedan ser consideradas más estratégicas que otras por más de un concepto (volveremos a ello), $\mathrm{y}$ por mucho que en estas partes haya «Laberinto» o «Teseo» en lugar de otras palabras más mundanas-. Nos lo recuerda RimmonKenan (1985: 399): el modo de emergencia más habitual del tema es la implicitación; y es en este sentido que una formulación explícita del tema en el texto sirve a menudo, precisamente, de obstáculo a la percepción de un tema latente más importante. Hechos los preámbulos necesarios, pasemos ya al análisis de los textos objeto de este escrito $^{2}$.

2 Doy ambos textos en apéndice. Las cifras y letras en negrita que aparecen en el texto de Borges son mías; y acompaño la versión del poema de Ferrater al castellano de su correspondiente original catalán. 


\section{EL LABERINTO}

«Un caos de palabras heterogéneas, un cuerpo de tigre o de toro, en el que pulularan monstruosamente, conjugados y odiándose, dientes, órganos y cabezas, pueden (tal vez) ser imágenes aproximativas» de la Ciudad de los Inmortales, una ciudad situada en el núcleo mismo de una intrincada red de laberintos. Lo dice, en el relato «El inmortal» (el primero de El Aleph, de 1949), Flaminio Rufo, el narrador del manuscrito que ocupa la parte central del texto. Habrían de pasar más de tres décadas para que Borges diera con una imagen mucho más aproximada, exacta casi, de la realidad del Laberinto mítico. Una imagen, no obstante, situada no en el nivel de la elocutio retórica, como las de Flaminio, sino en el de la dispositio. Expresado en pocas palabras, podríamos decir que «El Laberinto» no trata del laberinto de Creta, sino que se propone al lector como si lo fuera, y esto ya desde la declaración inicial —《Este es el laberinto de Creta»-. La efectividad del texto borgiano radica en el hecho de que la pertinencia de una declaración tan provocadora como ésta es mostrada, y por ende demostrada, a lo largo de todo el recorrido. El recurso del que para ello se sirve el narrador es harto convincente: un volver a empezar a partir ya de esta primera frase, y que, una vez leído el texto, conforma en nuestra conciencia la apariencia final de una suerte de icono del objeto. Gráficamente, tendríamos más o menos la siguiente figura (donde queda claro que el único segmento textual no repetido es 5e, el último; véase asimismo el texto en apéndice):

\section{FIGURA I}

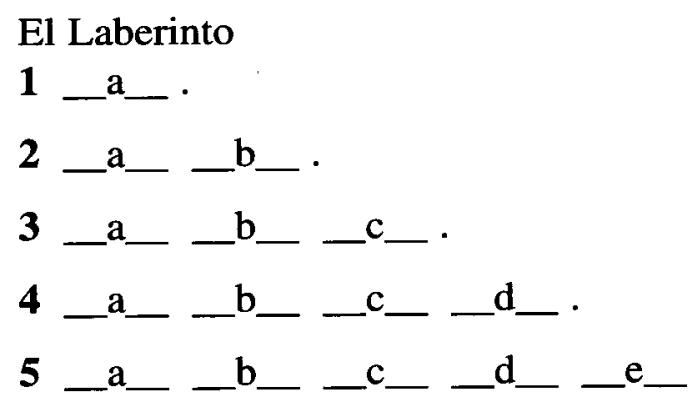

Este laberinto tiene salidas ciegas (no hay en él progresión sin suspensión). En la figura, estas salidas están representadas por los cuatro puntos que bloquean la continuación del trayecto y que obligan, pues, 
al lector a volver sobre sus pasos y buscar otra posibilidad ${ }^{3}$. En principio, la salida definitiva de este laberinto discursivo, como la de cualquier otra construcción verbal, debe encontrarse inmediatamente después de las últimas palabras del texto, las cuales tienen el cometido, desde un punto de vista pragmático, de asegurar la ruptura del contacto entre él y su lector. Un contacto, claro está, iniciado en el título. Pues bien, no es nada aventurado sostener que también esta última salida es problemática, y ello en virtud del hecho de que la palabra final («laberinto») envía al lector, de nuevo, a lo que, vaya ingenuidad la suya, pensaba haber dejado atrás tiempo ha, inmediatamente antes de iniciar la lectura del íncipit. Nos referimos, claro está, al título («El Laberinto»). Más gráficamente:

\section{FIGURA II}

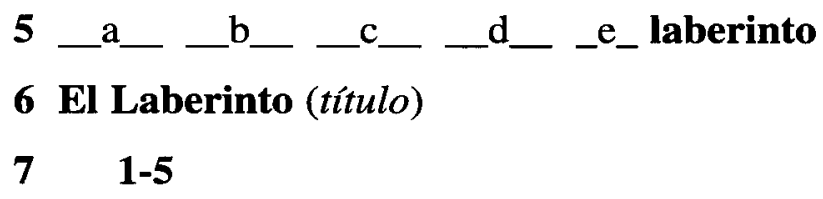

Así pues, la serie limitada de regresos internos que hemos intentado representar en la figura I (diez en total: uno en 2 , dos en 3 , tres en 4 y cuatro en 5) se duplica con un retorno, esta vez infinito (o eterno, si se prefiere término más mítico aunque menos borgiano), al título y al texto todo ${ }^{4}$. Al fin y al cabo, la vocación funcional del laberinto cretense era la misma que la de la prisión. El laberinto es una jaula para el animal (léase Minotauro), una cárcel para el hombre. Y, como la infeliz pantera del poema borgiano del mismo título, condenada tras los fuertes barrotes a un monótono camino de prisionera ${ }^{5}$, el lector, justo cuando creía estar a punto de recuperar la libertad, se ve defini-

3 Es preciso subrayar que éste es un camino de salida, no de entrada, pues, por lo general, esta última no conlleva dificultad alguna. El ovillo de hilo que Ariadna da a Teseo tiene por única función facilitarle el regreso.

4 Brion (1964: 359-360) distingue agudamente el laberinto, por una parte, del eterno retorno, por otra: en el primero, «on peut supposer que le promeneur pourra passer un millier de fois dans le même couloir et laisser inexplorés une quantité de sentiers dans lesquels il ne se sera pas aventuré»; el segundo, por el contrario, es «un mouvement circulaire qui entraîne le voyageur à repasser un nombre infini de fois par les mêmes points selon les prescriptions d'une continuité rigoureuse». Siguiendo esta distinción, podríamos decir que el texto de Borges plantea la posibilidad de un laberinto provisorio, transformado en eterno retorno a partir de la segunda vez que es recorrido.

5 En El oro de los tigres (1972). 
tivamente cautivo. Una vez dentro del laberinto, después de leída la primera frase del texto, empieza para él una búsqueda sin salida. No hay mejor ejemplo de recursividad ${ }^{6}$. Ni tampoco, quizá, de narcisismo ${ }^{7}$.

La metáfora final del texto, el tiempo como laberinto en el que el narrador - acompañado, cómo no, de María Kodama - está perdido, guarda sin duda relación con la naturaleza misma del lenguaje. A este respecto, Borges es muy claro en algunos de sus textos teóricos. Leemos, por ejemplo, en «Nueva refutación del tiempo»": «tan saturado y animado de tiempo está nuestro lenguaje que es muy posible que no haya en estas hojas una sentencia que de algún modo no lo exija o lo invoque». Las formas en que el tiempo «anima» el lenguaje son muy diversas. No obstante, la más patente es su misma índole secuencial, no simultánea. En efecto, los elementos de las lenguas verbales tienden a disponerse en una sucesión temporal que excluye que más de uno de ellos pueda darse en la misma posición. La sucesividad sígnica requiere por tanto, por parte del descodificador, una espera semiótica (Simone, 1990: 46) que concluye en el momento en que se tienen buenas razones para considerar que todo el conjunto de signos se ha manifestado. Pues bien: la serie de regresos internos a que nos obliga «El Laberinto» no hace más que subrayar y hacer perceptible para el lector el carácter dilatorio, y por ende temporal, del lenguaje. Roland Barthes es quizá quien mejor ha explicado este

6 El texto de Borges haría las delicias de cualquier generativista. Es sabido que, para la gramática generativa, la recursividad es la propiedad de las lenguas naturales que explica la capacidad real de los hablantes para producir y comprender nuevas oraciones, y caracteriza a las reglas que pueden ser aplicadas a una frase un número teóricamente infinito de veces. Si todo nombre puede ser complementado por una frase y en ésta aparece un nombre, éste último podrá a su vez ser de nuevo complementado por otra frase en la que podrá existir un nombre..., y así indefinidamente. Tomemos como ejemplo los tres primeros segmentos de «El Laberinto»: el SN «laberinto de Creta» es complementado por la frase «cuyo centro fue el Minotauro», la cual contiene un nombre («Minotauro») que es, a su vez, complementado por la frase «que Dante imaginó como un toro con cabeza de hombre»; la frase siguiente - «en cuya red de piedra se perdieron tantas generaciones»- es un segundo complemento de «laberinto de Creta».

Los teóricos procedentes de filas no propiamente lingüísticas prefieren, a recursividad, el vocablo circularidad; éste es el término que usa, por ejemplo, Jan Baetens (1993) en un estimulante análisis llevado a cabo en tres frentes distintos (el primero interno - textual-, los dos restantes externos - paratextual el uno, «material» el otro-): el texto, el peritexto y el soporte de la obra (los términos «paratexto» y «peritexto» proceden de Genette, 1982 y 1987 , respectivamente).

7 El carácter especular de la producción de Borges ha sido reiteradamente señalado por sus comentaristas; valgan como muestra de ello las tres citas siguientes: «arte caracterizado por volverse sobre sí mismo para contemplar la forma de su propia actividad» (Wheelock, 1966: 9), «necesidad de sí» (Cuperman, 1975: 12), «narración que se autoanaliza» (Barrenechea, 1975).

8 Otras inquisiciones (1952). 
carácter paradójico de la dinámica del texto: las frases apremian el desarrollo de la historia, pero el código hermenéutico —constituido por el conjunto de unidades que tienen la función de articular una pregunta, su respuesta y los accidentes que pueden preparar la pregunta o retardar la respuesta (Barthes, 1970: 24) - ejerce una acción contraria: tiene que disponer retrasos en el flujo del discurso. Para Barthes serían morfemas dilatorios, por ejemplo, el equívoco, la respuesta parcial, la respuesta suspendida, y, naturalmente, el bloqueo. Así pues, la metáfora que asimila el tiempo al laberinto sólo podría sorprender, como mucho, fuera de todo contexto: aquí, al final de un texto-laberinto por entero construido a partir del enigma («qqué se nos va a decir ahora?», nos hemos preguntado, como mínimo, cuatro veces ${ }^{9}$ ) no necesita más razones.

«La arquitectura del Laberinto es como la producción de un texto». Son palabras de Nicolás Rosa (1969: 140), uno de los críticos que mejor ha entendido a nuestro autor. Para apoyar esta afirmación, Rosa nos da una lección de historia y de arte. Parte él de la idea de que el laberinto simbólico de la Edad Media - un universo semiótico cerrado- comienza a generar una separación entre el laberinto como símbolo y el laberinto como puro procedimiento. El valor de símbolo hermético se degrada en pura ornamentación preciosista, y el elemento decorativo cobra significación por sí mismo. En el universo cristiano primitivo, el Laberinto velaba un signo mayor (fuera éste Dios, la Salvación o el Templo). La obliteración semiótica de que será objeto más tarde hará de él, sólo, una imagen de sí mismo, una ficción. Y este complejo proceso de desemantización se refleja en la textualidad borgiana. El espacio mítico del laberinto se ha convertido en el espacio de la literatura. Y, si esto ha podido ser así, hay que añadir, es gracias a una metáfora de sabor antiguo y culto: aquella que asemeja dos artes aparentemente tan distintas como la arquitectura y la literatura. Una letra es una piedra, escribir es construir. De Quintiliano (que compara el exordio con el frontón) a Gérard Genette (para quien los paratextos son umbrales, seuils), la metáfora de la literatura como arquitectura ha recorrido ya un largo trecho. Consecuentemente, no pecará de audaz quien vea detrás del yo narrador del texto de Borges - ese yo perdido en el Laberinto junto con María Kodama - la figura no de Teseo, sino la mucho más modesta — la mucho menos mítica, permítasenos tal licencia- de Dédalo, el arquitecto del Laberinto de Creta ${ }^{10}$. Hay que

9 En concreto, inmediatamente antes de $2 b, 3 c, 4 d$ y $5 e$ (cf. fig I y texto en apéndice).

10 También aquí Borges sorprende al lector: a pesar de que Ariadna nunca estuvo dentro del Laberinto, aquél supone de entrada que «María Kodama» y «yo» son versiones modernas de Ariadna y Teseo. 
tener en cuenta también que, según una tradición no regular del mito, el Laberinto habría atrapado a su propio creador, ignorante él mismo de la salida. Sólo que, por lo que parece, nuestro narrador no tiene la suficiente maña para fabricarse unas alas y escapar volando ".

\section{TESEO}

Cambiamos de texto. Y de metáfora. Gabriel Ferrater apela desde los tres primeros versos de «Teseo», aunque de una forma algo alusiva, a nuestro lenguaje más común, a nuestra experiencia lingüística más cotidiana. Cuando confesamos, en el curso de la explicación o del discurso de otro, que hemos perdido el hilo (quizá porque esta explicación o este discurso está lleno de cabos sueltos), o cuando decimos que Fulano urdió un buen pretexto o tramó un engaño con sus tejemanejes, usamos la misma metáfora que el poeta: el texto es un tejido. Es una metáfora, podríamos decir, que vivimos, para citar un libro ya clásico sobre el tema de Lakoff y Johnson $(1980)^{12}$. El mismo Quintiliano se servía de la palabra textus (participio pasado de texere) para referirse al mundo de las letras. Justificaba la metáfora, por aquel entonces, el aspecto de compacticidad que presentaba el manuscrito por la ausencia de espacios en blanco entre las palabras, pues, como es sabi-

11 Esto es lo que hizo Dédalo (junto con su hijo Ícaro). Y lo que hace - figuradamente, claro está-, al final, el protagonista de la novela de Joyce $A$ portrait of the artist as a young man (no en vano es Stephen Dedalus su nombre). Como se recordará, la obra concluye con unas pocas páginas del diario del joven, que se prepara para dejar Irlanda: Dublín lo tiene aprisionado, y debe, pues, «ponerse alas» para escapar de la ciudad y seguir su vocación de artista. En el texto del día 16 de abril los brazos de las rutas y de los grandes barcos se le abren y, junto con las voces, le llaman y «baten las alas» de su exultante juventud. La última frase del libro - corresponde al día 27 de abril-es una invocación y una petición a Dédalo: «Old father, old artificier, stand me now and ever in good stead».

12 Metaphors we live by. José Antonio Millán y Susana Narotzky, autores de la Introducción a la versión española, enriquecieron el libro estudiando precisamente las metáforas con que se expresa o se puede expresar en español la idea según la cual el discurso o el discurrir es un hilo. Además de trazar un recorrido muy esclarecedor por los avatares históricos de la metáfora, ensayan una clasificación iluminadora también para nuestro propósito: así, dependiendo de la naturaleza del concepto, «la metáfora recoge el aspecto de directriz (tipo "hilo de Ariadna"), de materia prima para elaboraciones complejas, o de soporte en el que engarzan otros elementos». En «Teseo» la metáfora recoge los dos primeros aspectos señalados por Millán y Narotzky: el hilo que aparece en el primer verso es un hilo conductor; al mismo tiempo, es hilo la materia de que están hechos los «tapices» (v. 3), la «trama» (v. 8). 
do, la cadena hablada era representada sin ninguna interrupción visual, como un conglomerado de signos sólidamente unidos — sólidamente tejidos- entre sí $^{13}$.

¿De qué recursos se puede valer el poeta para hacer que su texto se asemeje a un hilo sin faltarles al respeto a las convenciones de nuestra escritura, tan legible y tan clara y con sus ineludibles blancos interléxicos? Por lo pronto, será preferible a las estrofas la ausencia de las mismas (pues, al igual que el espacio interléxico, el espacio interestrófico corta el hilo). En segundo lugar, serán preferibles a los versos largos los versos cortos (pues el hilo es delgado). Y, en tercer y último lugar, serán preferibles, a cinco versos, veinticinco (pues el hilo es largo). Al igual que «El Laberinto» de Borges, el «Teseo» de Ferrater tiene vocación de icono: sin estrofas, y con nada menos que veintiséis versos de sólo cinco sílabas, satisface con creces las tres condiciones que acabamos de mencionar. No obstante, se nos dirá con razón: “¿cómo podemos estar tan seguros de que el hilo del que se nos habla en el primer verso se refiere al mismo poema «Teseo» en lugar de hacerlo a una realidad exterior a éste? ¿Qué evidencias tenemos de que este hilo es metapoético?" En este punto de la discusión, volver a las palabras de Ayala-Dip con las que hemos empezado - y que, como se recordará, subrayaban el hecho de que, en literatura, el espíritu de la modernidad había significado la asunción de que el único principio que le quedaba al poema era su propia realidad-, sería, cuando menos, insuficiente.

Vamos pues a recabar ayuda de otro teórico: se trata de Philippe Hamon. En uno de sus estudios más fecundos (Hamon, 1977), el francés explora la idea de que el texto literario contiene su propio sistema de paráfrasis, su propio metalenguaje. Hamon demuestra con multitud de ejemplos que los elementos de este sistema tienden a concentrarse y a desarrollarse en ciertos lugares del texto. Son lugares sobredeterminados desde un punto de visto semántico, privilegiados, o, como les

13 No se nos escapa que también Borges usaba la metáfora en «El Laberinto»: el Laberinto es una red de piedra (segmento $3 \mathrm{c}$ ). Sin embargo, en la prosa borgiana tiene mucho más peso el significado «texto como construcción» que «texto como tejido», muy lateral. Es casi enfermiza - maníaca - la frecuencia con la que Borges utiliza la expresión «red de piedra» (o «redes de piedra») o similares en los textos en los que el motivo del laberinto tiene alguna presencia; sólo cuatro muestras: el poema (en $E l$ hacedor) «Ariosto y los árabes», los poemas (en Elogio de la sombra) «Laberinto» y «El laberinto», y la prosa (en Los conjurados) «El hilo de la fábula».

También la vida (o uno mismo) puede ser un hilo (en general enmarañado), sobre todo cuando es la de un poeta (pues de ella se nutren sus textos); leemos en el «Poema inacabat» (ausente de Mujeres y días; cf. nota 1): «...del pueblo/donde se enredó la madeja/del hilo que soy». 
llama él, estratégicos. Son lugares de este tipo, por ejemplo, las junturas entre estrofas y entre capítulos, los blancos, los puntos y aparte, y, claro está, el título y el inicio y el final del texto. Por lo que respecta a los procedimientos usados en estos lugares, nos interesan aquellos que Hamon etiqueta con el nombre de implícitos, y que consisten en el desarrollo de un discurso que, metafóricamente, describe el proceso mismo de la lectura. Así, es frecuente que en el íncipit o inicio del texto un personaje espere algo, atraviese un umbral, entre en un lugar cerrado (el lector es alguien que penetra por primera vez en un texto nuevo), y que, simétricamente, en el éxplicit o final del texto el narrador parafrasee su propio discurso usando una temática clausular estereotipada que remita a la idea de una terminación: son ejemplos de ello motivos como la muerte, el silencio, la noche, el cierre, la partida (el lector es alguien que sale del texto). En «Teseo» tenemos un hilo en el primer verso y unas mujeres que esperan en el último. Hay alguien que vuelve lleno de temor (no pisa fuerte), regresa, quiere salir. Parece un trayecto difícil - un trayecto de laberinto-, y en él la única ayuda es un hilo. Quien vuelve es Teseo; las mujeres que le esperan son Ariadna («juntas», como se dice en el penúltimo verso, son una sola mujer), y saben que él puede salir porque son ellas quienes le han dado el hilo. De forma similar, la lectura de un poema requiere un esfuerzo: entre el mundo de la realidad y el mundo de la ficción hay un vacío, y cualquier transición del uno al otro será bien recibida. El lector necesita un hilo que ilumine el camino que va a iniciar, que le oriente a través del texto y que le permita salir de él con ciertas garantías de que ha comprendido lo que se le ha querido decir. Todo lector es Teseo. A estas alusiones del texto a sí mismo que encontramos en «Teseo» cabe añadir un dato más: ese tú sistemático, esa segunda persona. Hay pocas actividades tan solitarias y tan individuales como la lectura (quizá sólo la escritura se le podría comparar). A quien habla la voz narrativa es al lector ${ }^{14}$.

«Teseo» es el último poema de Les dones $i$ els dies. Es un poema terminal. Es probable que sea esta circunstancia — nada banal, por otra

14 Y esta interpretación no excluye otra según la cual el tú sería un disfraz del yo, el resultado de la observación distanciada de sí. Bousoño (1952) diría que el yo del personaje poemático se habría desdoblado en un tú al que aquél se dirigiría. En otras palabras, la voz emisora del texto habría tenido la precaución de tomar la suficiente distancia psíquica del asunto que pretendía abordar como para que le hubiera sido posible objetivizarse. Naturalmente, el yo existe; pero reflejado, embebido - dice Bousoño (1952: II: 386) - en un supuesto tú interlocutor que guarda las formas y permite no sonrojarse. Un poco como cuando (pasamos del tú al él o ella) le cuento a alguien conocido algo que me preocupa a mí como si le preocupara a un amigo o amiga («¿Sabes?, una amiga mía tiene un problema...»). 
parte, como ya tendremos ocasión de comprobar - lo que indujo a Macià y Perpinyà (1986: 168) a afirmar que el poema es un resumen autopoético. Años más tarde Perpinyà (1991: 87) llegará a mayor precisión: quien nos habla - y nos ha hablado a lo largo de todo el libroha ido resiguiendo con fatiga los caminos de la memoria con el objeto de vencer el olvido y se ha representado o figurado en sus poemas. Es decir, que el narrador ha recorrido los rincones de su memoria para transformar sus recuerdos en literatura. Ahora, una vez la obra cumplida — nos encontramos al final del libro-, es el momento de regresar, y, si hay suerte, de salir. Y no es por azar, creemos nosotros, que el poema inicial de Les dones $i$ els dies (el simétrico de «Teseo», desde un punto de vista puramente posicional) lleve por título, justamente, «In memoriam» (el poema empieza con la declaración del narrador de que, cuando estalló la guerra, él contaba sólo catorce años y dos meses). Así pues, Les dones i els dies, leído a la luz de «Teseo», se presenta al lector como una incursión en el oscuro laberinto de la memoria del narrador, una incursión con su correspondiente entrada ( «In memoriam») y su correspondiente salida («Teseo»). Tanto más que ya en los versos 5-7 de «In memoriam» el narrador confiesa que, por aquella época (cuando estalló la guerra), descubrió la poesía. Así pues, el hilo que es «Teseo» es sólo, a fin de cuentas, un extremo: el primer cabo es «In memoriam» ${ }^{15}$.

15 En su prólogo a Mujeres y días (cf. nota 1), Arthur Terry afirma que el sentido «más importante» de «In memoriam» lo sugiere el título: «es un poema que evoca una época ya muerta, una época en que el autor justamente empezaba a reconocer ciertos campos de la experiencia que apenas habían comenzado a integrarse en sus impresiones del mundo exterior» (p. XVIII; las cursivas son mías). Rosa Cabré (1982) se arriesga a ir un poco más allá: aprovechando --o eso parece - parte de la idea de Terry, concluye que la obra poética de Ferrater se dibuja a lo largo de una línea que va desde «In memoriam» (por «In memoriam» sabemos cuándo Ferrater inicia su experiencia vital, y por este motivo el poema es necesariamente el primero del volumen, p. 29) hasta «Teseo» (donde el poeta, gracias al hilo que le ofrece la poesía, puede recuperar y salvar definitivamente la propia experiencia, p. 33), pasando por el poema central, «Poema inacabat» (donde el poeta plantea el sentido de la recuperación del pasado para un mejor conocimiento de sí, p. 29).

Para nosotros - y seguimos sólo la línea esbozada por Cabré-, el título del primer poema de Les dones $i$ els dies haría las veces de una especie de sombra tutelar sobre el resto de los poemas del libro, y sería, en este sentido, un título más o menos programático, más o menos instructivo acerca de cómo debemos nosotros leer no sólo $s u$ poema, sino también todos los que siguen a éste. Es cierto, como apunta Terry, que la experiencia formalizada en «In memoriam» es una experiencia inicial -y, por consiguiente, más susceptible que otras menos tempranas de ser muerta (de ahí el título, según Terry) - , pero es experiencia en el recuerdo, filtrada por una conciencia adulta al mismo título que el resto de experiencias formalizadas en Les dones $i$ els dies (el mismo Terry (p. XXIX) indica más adelante que «una gran parte de la poesía de Ferrater muestra su preocupación por la experiencia recordada, y especialmente por la manera en que la experiencia puede reconstruirse en la memoria»). 
La metáfora inicial del poema - la memoria es un laberinto- se la sirve al poeta, en parte, el mismo mito. En efecto, según una versión menos conocida que la del ovillo, lo que Ariadna le habría dado a Teseo es una corona luminosa. $Y$ es gracias a esta luz como el héroe habría encontrado su camino en la oscuridad del laberinto. Si la memoria tiene sede y está contenida en algún sitio, éste no puede ser otro que la cabeza, único lugar, asimismo, donde toda corona cumple o debería cumplir su función. Así pues, en el hilo que dora la sombría memoria de Teseo (vs. 1-2), Ferrater hace confluir magistralmente las dos versiones de este motivo del mito: es un hilo, pero, como la corona, luminoso. Un hilo que ilumina una oscura memoria. Y mentirosa, pues, al igual que la de Proust, selecciona el material y lo dispone un poco a su antojo, como si tuviera vida propia: los tapices-poemas donde se ha representado el poeta (vs. 3-4) son sombras espesas (v. 19); espeso es por fuerza el tapiz), traiciones (v. 21) a sí mismo ${ }^{16}$, mentira ${ }^{17}$.

«Els tapissos on t'has figurat»... Llegamos a la clave del poema, una muy sutil alusión a una pequeña obra maestra de Henry James: The figure in the carpet. Inteligentísima reflexión sobre la búsqueda del significado oculto de los textos y sobre la relación entre obra e interpretación, la novela relata las pesquisas de un joven crítico para encontrar la secreta intención general que subyace en la obra del escritor que más admira; naturalmente, el joven no obtendrá lo que codicia. En su fino y bello análisis de la obra, Iser (1976) explica el fracaso del crítico por su idea (equivocada) de lo que es el sentido: algo que puede ser sustraído al texto. La interpretación deja tras de sí la obra como cáscara vacía a causa del significado que le ha arrancado. En opinión de Iser, La figura de la alfombra sería, pues, una dura crítica al esfuerzo «arqueológico» - y filológico- de interpretación, que excava en zonas profundas y destruye, rompe el texto para descubrir un subtexto que resulte verdadero. En definitiva, lo que hace el crítico «tradicional», así como el lector común (lleno de

16 Evidentemente, los versos 20 y 21 constituyen al mismo tiempo un indirecto diálogo con el famoso episodio de Ariadna viendo desaparecer en el horizonte la nave de Teseo, que la ha abandonado, traicionado.

17 En el poema «El lector» (ausente de Mujeres y días) el narrador confiesa que no recuerda quién le dio un cortapapeles que conserva en su bolsillo desde hace ya veinte años. Como sea que no quiere «mentirse un recuerdo más» (el cortapapeles en cuestión le ha abierto miles de páginas que son recuerdos, mentiras de otros hombres), acaba afirmando (absoluta verdad) que se lo dio una mano. Por si hubiera alguna duda en relación con el sentido de estas palabras, en el poema siguiente («Aniversario», p. 249) el narrador califica la memoria de verdulera y mentirosa (vs. 4-5). Más explícito todavía es «Si puedo» (p. 103). Reproducimos sólo los seis primeros versos: «Alguna cosa ha entrado / en un poema que sé / que he de escribir, y no / sé cuándo, cómo o qué / querrá expresar. Si puedo / lo guiaré hacia ti». 
prejuicios), es producto de una confusión: para ambos, los textos de la literatura de ficción son, como los textos de significado discursivo, explicables. La declaración inicial de «Teseo» es un guiño. Con ella alude el narrador a dos formas de leer: la que busca tras las apariencias (donde puede haber, por ejemplo, mensajes esotéricos, ideas filosóficas sobre la vida y demás reducciones) y la que lo hace no más allá de ellas (como dice el novelista al crítico en el tercer capítulo de la novela de James, lo que éste debe encontrar en sus libros está tan encajado en ellos como el pie en el zapato). Naturalmente, la razón se la lleva esta última: no busquéis un significado oculto, pues no lo hay. Sólo hay figura, ningún fondo misterioso, ningún tesoro oculto. El sentido de los textos de ficción tiene carácter figurativo, no discursivo, y sólo se deja captar como imagen; como tal, en lugar de describir algo ya presente de antemano, encarna una representación de aquello que no existe ${ }^{18}$. Siendo $\longrightarrow$ queriendo ser-, pues, los poemas de Les dones $i$ els dies figuras (imágenes), «Teseo» nos invita a su lectura (a su experiencia) en lugar de a su explicación sustitutiva. A la luz de estas consideraciones, ¿qué tiene de extraño que el libro termine con la misma expresión con que empezó?

te esperan las mujeres

Mujeres y días (título)

¿Y que haya una tan evidente correspondencia entre el segundo sintagma del título del libro, por un lado, y el título y los dos versos iniciales del primer poema, por otro?

Mujeres y días (título)

IN MEMORIAM

Al estallar la guerra, yo tenía

catorce años y dos meses.

Les dones y els dies, mujeres y tiempo (memoria, la guerra, catorce años). Lo que en Borges se daba en el seno de un único

18 La versión al castellano es quizá más transparente («los tapices donde te has representado» es una expresión más «legible» que «els tapissos on t'has figurat»), pero escamotea al lector la alusión al texto de James. 
texto, en Ferrater sucede a escala multiplicada. Si quien ha hilado estos poemas sólo volverá a hallarse a sí mismo —un sí mismo que es una sombra y un propósito traicionero- a la salida del laberinto (eso se nos dice a partir del verso 18) es porque tal salida conlleva un volver adentro. Y con el suyo, el del lector: salimos de «Teseo» no para volver a la realidad exterior; tampoco para volver al poema. Salimos de «Teseo» invitados a reiniciar el camino por las ciento catorce pequeñas traiciones (cf. nota 1) en las que el narrador se ha figurado.

Ciento catorce pequeñas traiciones de las cuales la primera empieza con una afirmación rigurosamente verdadera: ciertamente, cuando estalló la guerra, Ferrater tenía catorce años y dos meses ${ }^{19}$. También María Kodama es alguien existente -el nombre aparecía de golpe (en el segmento $4 \mathrm{~d}$ de «El Laberinto») y sin previo aviso, y acompañaba, precediéndolo, a un «yo» anónimo. Girar ahora en torno a un género que se ha dado en llamar autoficción nos alejaría demasiado de nuestro tema. Valgan, sin embargo, unas pocas referencias. Colonna (1989: 54) lo ha definido como un dispositivo de enunciación que reposa sobre un protocolo nominal consistente en una relación de homonimia entre el autor y un personaje. La homonimia puede ser cifrada, por homología. Así, ciertas indicaciones del estado civil del autor permiten su ficcionalización: en «In memoriam» es el año de nacimiento; en «El Laberinto» el mecanismo nos parece más complejo, pues concurren un nombre propio y un cierto dato civil: diríamos que el nombre de una persona íntimamente vinculada al autor contagia e impregna al anónimo «yo» de realidad: «María Kodama» - «yo»- Jorge Luis Borges. Darrieussecq (1996: 377) ha estudiado el estatuto pragmático del género: ficcionalización de lo factual y factualización de lo ficticio; la autoficción es una aserción que se dice fingida y que al mismo tiempo se dice seria. Es el lugar de la palabra que escapa, una práctica de escritura ilocutoriamente désengagée. Para Filinich (1996: 206) la autoficción borra las fronteras entre enunciación real (en la

19 El lector puede comprobar la veracidad de parte de tal afirmación acudiendo a la cubierta posterior del libro, donde como es habitual se le informa del año de nacimiento del autor: 1922; tendremos que consultar otras fuentes para contrastar el resto del dato, los dos meses - leemos en el epílogo a Da nuces pueris (el primer libro de poemas de Ferrater, de 1960, integrado años después en Les dones $i$ els dies): «Vaig néixer a Reus, el 20 de maig del 22»; y en el prefacio de su hermano Joan a Gabriel Ferrater. Papers, Cartes, Paraules (Barcelona: Quaderns Crema, 1986): «Gabriel Ferrater va néixer el 20 de maig del 22, a Reus». 
cual están implicados autor y lector) y enunciación ficticia (cuyos protagonistas son narrador y narratario).

\section{TRES IMÁGENES: HILO, ÁRBOL, RED}

Hay tres laberintos (Eco, 1983: 383-384).

(1) El unidireccional o de itinerario único. Éste es el laberinto clásico, el de Knosos. Al entrar en él sólo se puede llegar al centro, y del centro sólo se puede encontrar la salida. Si lo desenrolláramos, en las manos nos encontraríamos un hilo. El hilo de Ariadna, que el mito presenta como el medio para salir del laberinto, es en realidad el laberinto mismo. En este laberinto debe haber un Minotauro, pues el recorrido conduce siempre adonde debe conducir y no puede dejar de conducir. Éste es el laberinto de Ferrater: el monstruo a vencer -el Minotauro- es el olvido.

(2) El manierista o Irrweg. A diferencia del anterior, este laberinto propone más de una opción. Salvo uno, todos los caminos conducen a un punto muerto, ciego (quien lo recorre comete errores, tiene que volver sobre sus pasos...). Si lo desenrolláramos, en lugar de un hilo tendríamos un árbol: una estructura de callejones sin salida. Podría ser útil, aquí, un hilo de Ariadna. No hay necesidad de Minotauro. Este es el laberinto de Borges. Eco diría que Borges se equivoca (o que nos miente, o que, impuro, mezcla tipos): su laberinto no es el de Creta, como nos dice en el íncipit de su texto (el laberinto de Creta pertenecería propiamente al primer tipo), ni tampoco es, como nos dice en el segmento $3 \mathrm{c}$, una red.

(3) La red. En este laberinto todo punto puede conectarse con cualquier otro punto. Es el único que no se puede desenrollar, pues, a diferencia de los otros dos, no tiene ni interior ni un exterior por el que entrar y hacia el que salir. Una red es un árbol más infinitos corredores que conectan los nudos del árbol. Podemos hablar de este tercer tipo de laberinto. Lo hace Borges en «Laberinto» (en Elogio de la sombra):

No habrá nunca una puerta. Estás adentro

Y el alcázar abarca el universo

$\mathrm{Y}$ no tiene ni anverso ni reverso

Ni externo muro ni secreto centro. 
Pero el lenguaje es insuficiente para mostrarlo (el lenguaje tiene sus limitaciones, y hay iconos imposibles). Quizá sólo el caligrama podría ${ }^{20}$.

\section{Referencias bibliográficas}

Ayala-Dip, J. E. (1993). «Benjamín, Baudelaire i el futur de la lírica». En Walter Benjamin i l'esperit de la modernitat, J. Llovet (ed.), 159-166. Barcelona: Barcanova.

BAETENS, J. (1993). «Qu'est-ce qu'un texte 'circulaire'?». Poétique 94, 215-228.

BARRENECHEA, A. M. (1975). «Borges y la narración que se autoanaliza». Nueva Revista de Filología Hispánica, 24:2, 515-527.

BARTHES, R. (1970). S/Z. París: Seuil.

BESA, J. (1996). «Un cami de Josep Carner i altres camins possibles». Revista de Catalunya 109, 130-139.

Bousoño, C. (1952). Teoría de la expresión poética. Madrid: Gredos, $1985^{7}$, 2 vols.

BRION, M. (1964). «Masques, miroirs, mensonges et labyrinthe». En L'Herne (Cahiers)Jorge Luis Borges, D. de Roux y J. de Milleret (comps.), 341363. París: Éditions de L'Herne, 1981.

CABRÉ, R. (1982). «Les dones $i$ els dies: notes de lectura». Faig 16, 27-35.

ColonNA, V. (1989). L'autofiction (essai sur la fictionnalisation de soi en littérature). París: EHESC. Tesis inédita.

CourTÉs, J. (1985). «Pour une sémantique des traditions populaires». Actes Sémiotiques - Documents VII, 65, 5-20.

CUPERMAN, P. (1975). «La negatividad en Borges». Ínsula XXX: 340, 1,12 y 15.

DarrieussecQ, M. (1996). «L'autofiction, un genre pas sérieux». Poétique 107, 369-380.

ECo, U. (1983). «El Antiporfirio». En De los espejos y otros ensayos, 358387. Barcelona: Lumen, 1988.

FILINICH, M. I. (1996). «La escritura y la voz en la narración literaria». Signa $5,203-217$.

20 Por esta razón sería más «propio», como título para el poema acabado de citar, «El laberinto» (en lugar de «Laberinto»). Por el contrario, el texto borgiano que ha sido objeto de análisis en este artículo, por su misma vocación icónica, no se resistiría en absoluto a un título sin determinante: como título, «Laberinto» focaliza sobre la forma (el contar, o el rema, en el uso que del término hace Genette 1987) y por consiguiente sugiere que el texto que le sigue es (o quiere ser leído/visto como si fuera) un laberinto, mientras que «El laberinto» focaliza sobre el contenido (lo contado, o el tema) y sugiere que su texto tratará de un o del laberinto. Para un análisis más detallado de las implicaciones que el uso de determinante en el título tiene en la lectura del texto, cf. Besa (1996). 
Genette, G. (1982). Palimpsestes. La littérature au second degré. París: Seuil.

- (1987). Seuils. París: Seuil.

Hamon, Ph. (1977). «Texte littéraire et métalangage». Poétique 31, 261-284. ISER, W. (1976). Der Akt des Lesens. Theorie Asthetischer Wirkung. Munich: Wilhelm Fink.

LAKOFF, G. y M. Johnson (1980). Metáforas de la vida cotidiana. Madrid: Cátedra, $1995^{3}$.

MACIÀ, X. y N. PERPINYÀ (1986). La poesía de Gabriel Ferrater. Barcelona: Edicions 62.

Oller, D. (1995). «El significat de la forma: tres poemes de Josep Carner». En Carneriana. Josep Carner, vint-i-cinc anys després, J. Subirana (ed.), 151-168. Barcelona: Proa.

- (1996). «El significado de la forma: un aspecto». En Mundos de ficción (Actas del VI Congreso Internacional de la Asociación Española de Semiótica. Murcia, 21-24 de noviembre, 1994), J. M. Pozuelo Yvancos y F. Vicente Gómez (eds.), vol. I, 145-150. Murcia: Universidad de Murcia.

PERPINYÀ, N. (1991). «Teoria dels cossos», de Gabriel Ferrater. Barcelona: Empúries.

RiMmON-KENAN, S. (1985). «Qu'est-ce qu'un thème?». Poétique 64, 397-406. RosA, N. (1969). «Borges o la ficción laberíntica». En Nueva novela latinoamericana 2, J. Lafforgue (comp.), 140-173. Buenos Aires: Paidós.

SimONE, R. (1990). Fundamentos de lingüística. Barcelona: Ariel, 1993. WHEELOCK, C. (1966). The Mythmaker: a Study of Motif and Symbol in the Short Stories of Jorge Luis Borges. Austin: University of Texas Press.

\section{APÉNDICE}

\section{El laberinto}

1a Este es el laberinto de Creta. 2a Este es el laberinto de Creta b cuyo centro fue el Minotauro. 3a Este es el laberinto de Creta b cuyo centro fue el Minotauro c que Dante imaginó como un toro con cabeza de hombre y en cuya red de piedra se perdieron tantas generaciones. 4a Este es el laberinto de Creta b cuyo centro fue el Minotauro $\mathbf{c}$ que Dante imaginó como un toro con cabeza de hombre y en cuya red de piedra se perdieron tantas generaciones $\mathbf{d}$ como María Kodama y yo nos perdimos. 5a Este es el laberinto de Creta b cuyo centro fue el Minotauro c que Dante imaginó como un toro con cabeza de hombre y en cuya red de piedra se perdieron tantas generaciones $\mathbf{d}$ como María Kodama y yo nos perdimos e en aquella mañana y seguimos perdidos en el tiempo, ese otro laberinto. 


\section{TESEU}

Un sol fil et daura la fosca memòria, corre pels tapissos on t'has figurat.

5 Tornes, tornes tu? No trepitges fort, $i$ et fas sofrir els ulls a seguir la trama pels vells corredors.

10 Salves esvorancs de por successiva, només que et llampeguin lluïssors de fe que, una mica idèntic,

15 algú que pots dir que és tu mateix, sempre fa cami amb tu. No retrobaràs la teva ombra espessa,

20 el dúctil propòsit amb què saps trair, fins que surtis on, a la llum del sol («quina? quina?» et crida

25 la gralla) plegades, t'esperen les dones.

\section{TESEO}

Un solo hilo te dora la sombría memoria, corre por los tapices donde te has representado. ¿Vuelves, vuelves tú? No pisas fuerte, $\mathrm{y}$ te haces sufrir los ojos siguiendo la trama por los viejos corredores.

Salvas simas de miedo sucesivo, sólo con que te refuljan reflejos de fe que, un poco idéntico, alguien que puedes decir que es tú mismo, siempre camina contigo.

No volverás a hallar tu sombra espesa, el dúctil propósito con que sabes traicionar, hasta que salgas adonde, a la luz del sol («¿cuál? ¿cuál?», te grita el grajo) juntas, te esperan las mujeres. 